\title{
In misleading histories: Key role of dermoscopy
} Anamnez farklı yönlendirdiğinde: Dermoskopinin anahtar rolü

๑ Gamze Erfan

Acıbadem Mehmet Ali Aydınlar University Faculty of Medicine, Department of Dermatology, İstanbul, Turkey

Keywords: Pink lesions, vascular features, dermoscopy

Anahtar kelimeler: Pembe lezyonlar, vasküler yapılar, dermoskopi

\section{Introduction}

Dermoscopy is a key technique used by dermatologists to diagnose pigmented and non-pigmented skin tumors ${ }^{1,2}$. Besides its traditional application, dermoscopy has been used in evaluating disorders in general dermatology such as inflammatory, hair, and infectious skin diseases with increasing reliability in recent years ${ }^{3-5}$. Additionally, previous studies have demonstrated its exceptional use in differentiating inflammatory lesions and non-melanocytic skin tumors ${ }^{6-8}$. As the basic approach for diagnosing non-melanocytic skin tumors relies on differentiating vascular structures, Herein, two different cases with distinct dermoscopic vascular structures, misleading histories, and similar clinical findings are presented.

\section{Case Reports}

\section{Case 1}

A 28-year-old female patient who had no personal or family history of any dermatological disease presented with a pruritic lesion that had been on her left shoulder. A solitary skin lesion appeared three months ago in millimetric size but had started to enlarged in diameter a week before coming to us. Physical and dermatological examinations revealed no findings on the whole body, including hair and nails, except for a $1 \mathrm{~cm}$ diameter, yellowish-white scaled erythematous plaque on her left shoulder (Figure 1). Furthermore, dermoscopic evaluation showed yellowish and whitish scales with regularly-distributed dotted vessels (Figure 2). Based on the clinical and dermoscopic findings, we prescribed a topical corticosteroid treatment for the patient. However, the patient refused the treatment and requested for a biopsy to rule out malignancy. Histopathological examination revealed parakeratotic hyperkeratosis with irregular acanthosis, thinning of the granular layer, and a neutrophilic microabscess within the stratum corneum, resulting in a diagnosis of psoriasis.

\section{Case 2}

A 52-year-old male patient with four months history of pruritic lesions was admitted to our outpatient clinic. Although he

Address for Correspondence/Yazışma Adresi: Gamze Erfan MD, Acıbadem Mehmet Ali Aydınlar University Faculty of Medicine, Department of Dermatology, istanbul, Turkey Phone: +90 5322232523 E-mail: gamzeerfan@gmail.com Received/Geliş Tarihi: 23.09.2021 Accepted/Kabul Tarihi: 03.11.2021 ORCID: orcid.org/0000-0003-0000-5568

Cite this article as: Erfan G. In misleading histories: Key role of dermoscopy. Turkderm-Turk Arch Dermatol Venereol 2021;55:210-2

CCopyright 2021 by Turkish Society of Dermatology and Venereology

Turkderm - Turkish Archives of Dermatology and Venereology published by Galenos Yayınevi. 
had no personal history of dermatological diseases, his mother had a history of psoriasis for almost 20 years. Believing that his lesions located on his back, trunk, and upper extremities were psoriatic plaques, the patient applied class 1 corticosteroid creams twice a day regularly since symptom onset without consulting a dermatologist. Physical and dermatological examinations revealed millimetric whitish scaled erythematous plaques on his back, arms, and trunk and yellowish-whitish scaled erythematous plaque with irregular borders on his left shoulder (Figure 3). Additionally, dermoscopic evaluation of his irregularlybordered plaque showed yellowish scales with irregularly-distributed dotted, glomerular, and linear vessels (Figure 4). On the other hand, the other millimetric papules that showed yellowish crusted scales with regularly-distributed dotted vessels were indicative of psoriasis based

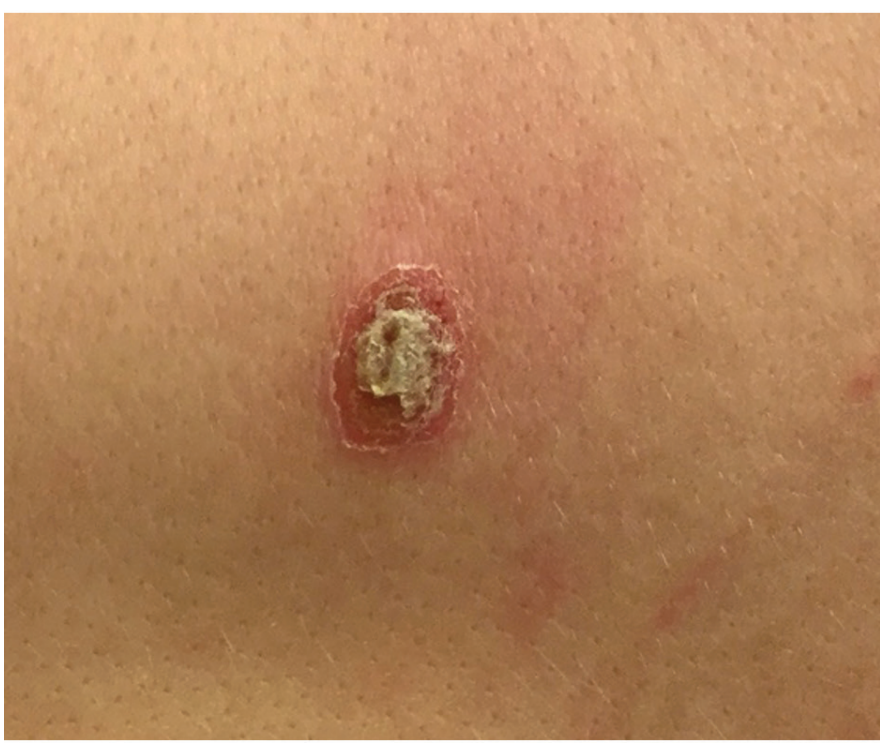

Figure 1. A 28-year-old female patient with a yellowish-white scaled erythematous plaque (1 cm diameter) on her left arm

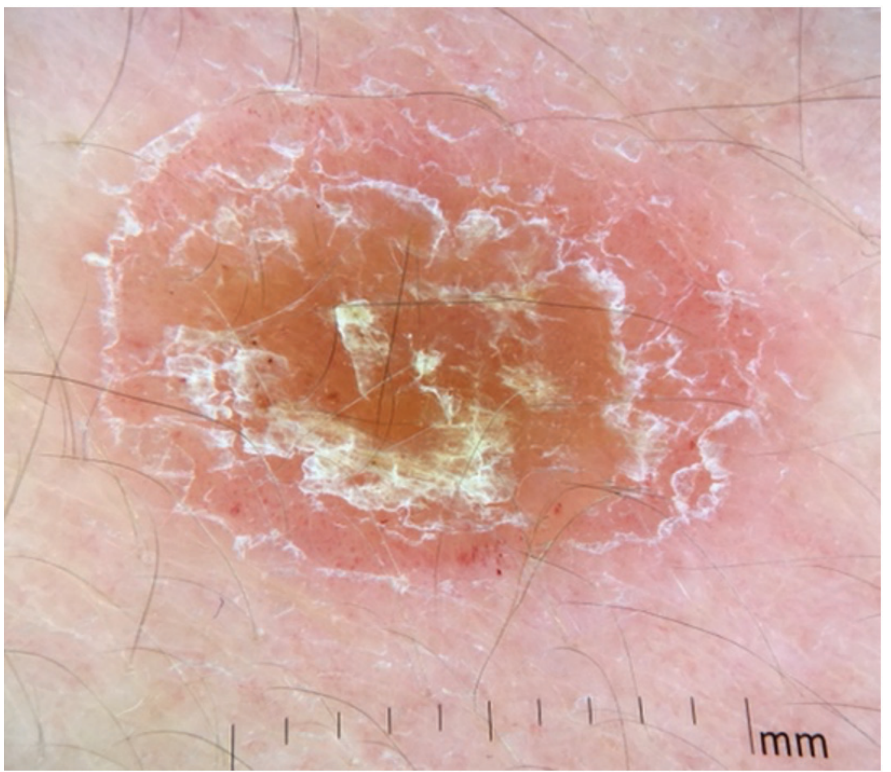

Figure 2. Dermoscopy x20: Yellowish and whitish scales with regularlydistributed dotted vessels. Diagnosis: Psoriasis vulgaris on dermoscopy. Based on histopathological examination of the biopsy specimen from his left shoulder which showed epidermal full thickness atypia of keratinocytes with granular layer loss and parakeratosis, we diagnosed the patient as having Bowen's disease.

\section{Discussion}

Dermoscopy plays a remarkable role in appropriately diagnosing conditions of patients with misleading histories and clinical clues because of its ability to reveal findings not visible to the naked eye. Especially in pink solitary lesions, the technique is able to differentiate pink tumors from inflammatory, infectious, or autoimmune diseases ${ }^{3-6}$.

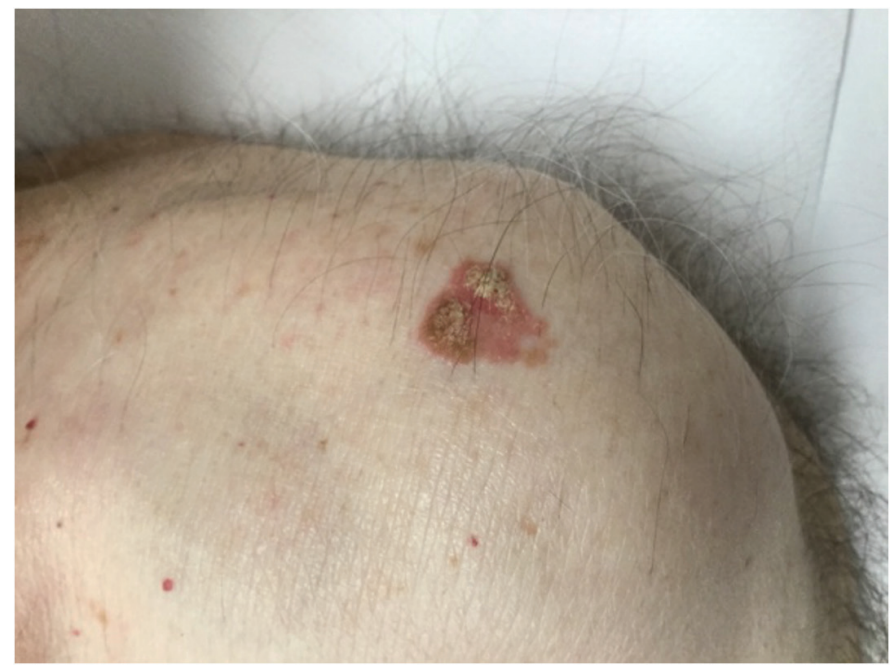

Figure 3. A 52-year-old male patient with a yellowish-white scaled erythematous plaque $(1.5 \mathrm{~cm}$ diameter) with irregular borders on his left arm

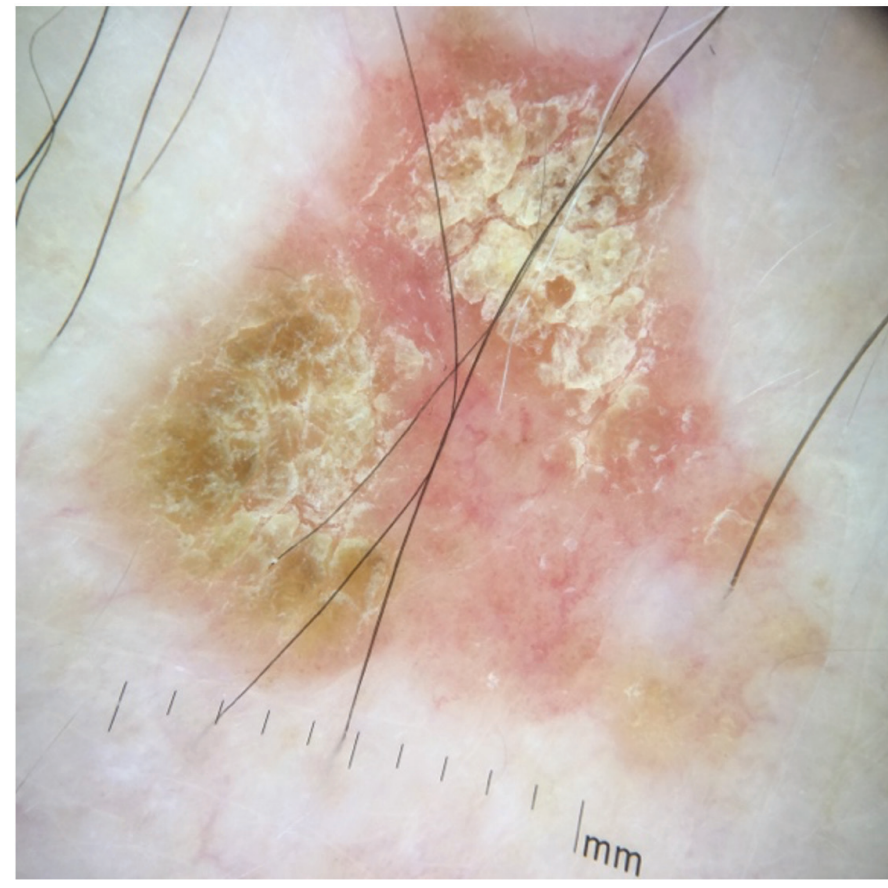

Figure 4. Dermoscopy $\times 20$ : Clusters of dotted and tortuous vessels with yellowish-whitish scale. Diagnosis: Bowen's disease 
For common diseases, like psoriasis or eczema, with unusual clinical pattern or history that can misguide clinicians, dermoscopy shows its magic and can be as effective as full-body examination ${ }^{4,5}$. But for performing perfect magic tricks, we need algorithms and better knowledge of clinical history.

For differentiating pink solitary lesions like the abovementioned cases, we suggest using proper algorithms ${ }^{7,9-11}$. Clinically, even though a solitary lesion seems inflammatory, applying a two-step algorithm to over-rule melanocytic or non-melanocytic tumors is essential for the dermoscopic approach ${ }^{9,10}$. Employing clinical assessment and detailed dermoscopy to determine whether a lesion belongs to tumoral or inflammatory diseases is also necessary ${ }^{3-6}$. For this, diagnosing pink tumors requires a five-step algorithm ${ }^{11}$. Previously, Zalaudek et al. ${ }^{10}$ suggested a three-step algorithm for dermoscopic diagnosis of a nonpigmented skin tumor, which depended on vascular morphology, the architectural arrangement of the vasculature, and other optional clues. This expanded to five steps as follows: Clinical assessment, vascular morphology, the architectural arrangement of the vasculature, specific pattern, and dermoscopic clues (in order) ${ }^{11}$. Additionally, examining the detailed vascular features of the disease is also needed. Using this algorithmic approach in clinical practice, as in case 2, provides the opportunity to identify non-melanocytic tumor in a patient with numerous psoriatic plaques.

Previously, studies have investigated the dermoscopic patterns, which were first described in the beginning of 2000s, and the variability of these patterns in psoriatic lesions according to the anatomic sites ${ }^{7,8,12,13}$. We now know fully well that typical vascular features show no difference in terms of lesions localization. This makes monomorphic, symmetrically distributed, dotted vascular structures with similar diameter and shape the most important dermoscopic features, mirroring the histopathological findings of spiraled capillaries within dermal papillae ${ }^{8-13}$. Additionally, white scaling suggests high probability of psoriasis. In differential diagnosis, the color and distribution of scales and red-dotted or globular vascular structures in a whole lesion can also be attributed to Bowen's disease.

Bowen's disease is described as a variant of in situ squamous cell carcinoma. Dermoscopic vascular features described in non-pigmented Bowen's disease lesions are specifically glomerular vessels ${ }^{10,14}$. Another vascular pattern variant involves small dotted vessels that often appear within the same lesion with glomerular vessels. These vessels are densely packed clusters or groups that differ from psoriatic lesions. Furthermore, these vessels transform into polymorphic vascular structures during invasive carcinoma stages. Additionally, scales on lesions and white halo around the vessels can be seen dermoscopically ${ }^{10-14}$.
Vascular structures provide important clues in dermoscopy. Diagnosing even the easiest and most common conditions can be difficult without dermoscopy since clues may be hidden in vascular patterns. In daily clinical practice, each lesion should undergo a detailed dermoscopic evaluation on top of detailed clinical history and examination. Furthermore, a dermoscopic evaluation of "every and each lesion" enables us to double-check our diagnosis of pink lesions, providing us a chance to improve our dermoscopic practices in the future.

\section{References}

1. Argenziano G, Albertini G, Castagnetti F, et al.: Early diagnosis of melanoma: what is the impact of dermoscopy. Dermatol Ther 2012;25:403-9.

2. Lallas A, Argenziano G, Zendri E, et al.: Update on non-melanoma skin cancer and the value of dermoscopy in its diagnosis and treatment monitoring. Expert Rev Anticancer Ther 2013;13:541-58.

3. Verzi $A E$, Lacarrubba F, Dinotta F, Micali G: Dermatoscopy of parasitic and infectious disorders. Dermatol Clin 2018;36:349-58.

4. Errichetti E, Stinco G: Dermoscopy in General dermatology: a practical overview. Dermatol Ther (Heidelb) 2016;6:471-507.

5. Sgouros $D$, Apalla $Z$, loannides $D$, et al.: Dermoscopy of common inflammatory disorders. Dermatol Clin 2018;36:359-68.

6. Giacomel J, Zalaudek I: Pink lesions. Dermatol Clin 2013;31:649-78.

7. Errichetti $\mathrm{E}$, Zalaudek I, Kittler $\mathrm{H}$, et al.: Standardization of dermoscopic terminology and basic dermoscopic parameters to evaluate in general dermatology (non-neoplastic dermatoses): An expert consensus on behalf of the International Dermoscopy Society. Br J Dermatol 2020;182:454-67.

8. Lacarrubba F, Nasca MR, Micali G: Videodermatoscopy enhances diagnostic capability in psoriatic balanitis. J Am Acad Dermatol 2009;61:1084-6.

9. Togawa Y: Review of vasculature visualized on dermoscopy. J Dermatol 2017;44:525-32.

10. Zalaudek I, Kreusch J, Giacomel J, Ferrara G, Catricalà C, Argenziano G: How to diagnose nonpigmented skin tumors: a review of vascular structures seen with dermoscopy: part II. Nonmelanocytic skin tumors. J Am Acad Dermatol 2010;63:377-86

11. Zalaudek I: How to assess a given non-pigmented lesion. Dermatoscopy of non-pigmented skin tumors (pink-think-blink) (eds). In: Zalaudek I, Argenziano G, Giacomel J. Florida, Taylor\&Francis Group, 2016;21-39.

12. De Angelis R, Bugatti L, Del Medico P, Nicolini M, Filosa G: Videocapillaroscopic findings in the microcirculation of the psoriatic plaque. Dermatology 2002;204:236-9.

13. Micali G, Nardone B, Scuderi A, Lacarrubba F: Videodermatoscopy enhances the diagnostic capability of palmar and/or plantar psoriasis. Am J Clin Dermatol 2008;9:119-22.

14. Zalaudek I, Giacomel J, Schmid K, et al.: Dermatoscopy of facial actinic keratosis, intraepidermal carcinoma, and invasive squamous cell carcinoma: a progression model. J Am Acad Dermatol 2012;66:589-97. 